\title{
LA HIPOTESIS DE DOMAR SOBRE LAS CAUSAS DE LA SERVIDUMBRE O LA ESCLAVITUD EN UNA COLONIA HISPANOAMERICANA: CONTRASTE Y REFORMULACION*
}

\author{
MARIO HECTOR PASTORE ** \\ Universidad de Miami
}

Según Domar, las causas de la esclavitud o de la servidumbre pueden encontrarse en la escasez relativa de trabajo en relación con la tierra y en la intervención gubernamental que, entre 1550 y 1650, llevaron a la servidumbre al campesinado ruso, anteriormente libre ${ }^{1}$. Formas similares de trabajo forzado y libre surgieron aproximadamente al mismo tiempo, aunque no en el mismo orden, en una serie de colonias periféricas, españolas y portuguesas, en América, donde la tierra era igualmente abundante en relación con el trabajo. Propongo, por lo tanto, contrastar la hipótesis de Domar verificando si sus predicciones son consistentes con la experiencia de una colonia periférica española bastante representativa, como es Paraguay ${ }^{2}$. Resumiré la hipótesis en la sección 1, describiré brevemente las formas de trabajo forzado y libre que surgieron en el caso de prueba de la sección 2, contrastaré las implicaciones de la hipótesis con la evidencia empírica en la sección 3 y reformularé ciertos aspectos de la hipótesis para que sean consistentes con el caso estudiado en la sección 4. Idealmente, la hipótesis reformulada se debería volver a contrastar con una visión más amplia de la historia de Paraguay, así como con la de otras colonias periféricas y de las regiones que Domar examinó. No obstante, y por limitaciones de espacio, solamente apuntaré en

* La investigación para este trabajo se llevó a cabo en las bibliotecas Olin, Newberry y Regenstein, de Ithaca, Nueva York, y Chicago, Illinois. Doy las gracias a la Society for the Humanities, de la Universidad de Cornell; el National Endowment for the Humanities y el Latin American Studies Program, de la Universidad de Chicago, por su ayuda económica. Las primeras versiones del trabajo fueron presentadas en el Primer Simposio Internacional de Estudios Latinoamericanos, celebrado en Asunción en junio de 1988, y en la 48." reunión anual de la Economic History Association, celebrada en Detroit en septiembre de 1988 .

**: La versión final de este trabajo fue escrita durante mi estancia en el Departamento de Economía y en el Centro de Economía Política de la Universidad de Washington. San Luis. Agradezco los comentarios de Evsey Domar, Gabriel Tortella, Tom Davis, Luis Galeano, Stanley Engerman, Branislava Susnik, Robert Higgs y Rafael Eladio Velázquez, si bien asumo toda la responsabilidad por cualquier error u omisión.

'Domar (1970), pp. 18-20.

2 Para una descripción de estas zonas periféricas, véase Lockhart y Schwartz (1983), pp. 253-304. 
la sección 5 que las implicaciones teóricas de la hipótesis reformulada son consistentes con otros aspectos de la historia laboral y militar del Paraguay colonial.

1. Domar sostuvo que el campesinado libre aparece si la tierra es abundante y la competencia por trabajadores entre los terratenientes es libre. Teniendo en cuenta sólo dos factores, trabajo y tierra abundante de fertilidad uniforme, el producto marginal del trabajo será constante e igual al producto medio. La competencia entre los terratenientes hará subir los salarios hasta que se igualen al producto marginal del trabajo y, así, toda la producción se pagará a los trabajadores en forma de salario. La tierra no producirá rentas. Dado que los terratenientes no contratarán trabajadores a menos que las rentas sean positivas, y que los trabajadores no querrán ser contratados por menos de lo que pueden ganar trabajando en sus propias tierras, de fácil obtención, aparecerán granjas familiares de aproximadamente el mismo tamaño. El gobierno podrá obtener ingresos gravando al campesinado con impuestos directos o indirectos, pero no gravando las rentas de la tierra. Las fuerzas económicas por sí mismas, sin interferencia gubernamental, determinarán la estructura institucional. La limitación del derecho a poseer tierras no modificará significativamente este resultado: los campesinos trabajarán ahora por un salario, pero la competencia entre los terratenientes mantendrá los salarios elevados en relación con la producción total. Aunque se amplíe el número de factores a tres. los resultados permanecerán prácticamente inalterados, con tal de que la tierra sea abundante y no se obstaculice la competencia. El norte de Estados Unidos en el período colonial y en el siglo xIX es un ejemplo de este caso.

La servidumbre o la esclavitud aparecerán cuando el trabajo sea escaso en relación con la tierra y, además, los gobiernos intervengan para vincular a trabajadores y terratenientes, debido posiblemente a problemas de Hacienda pública: al eliminar la competencia entre los terratenientes por los campesinos se permite que aquéllos se apropien del producto marginal del trabajo por encima de un mínimo de subsistencia, excedente con el que pueden mantenerse a sí mismos y equipar los ejércitos necesarios para hacer la guerra a otros Estados. La vinculación de la tierra no logrará el mismo resultado, por los motivos ya mencionados. Es necesario observar aquí que Domar consideraba equivalentes la servidumbre y la esclavitud, y que utilizaba los dos términos indistintamente.

La desaparición de la esclavitud es, para Domar, más segura en una economía tradicional que en otra donde es habitual la innovación tecnológica. Para nuestros fines es más relevante una economía tradicional donde, según Domar, la esclavitud desaparece como resultado de un mecanismo malthusia- 
no: el crecimiento de la población lleva a una caída en el producto marginal del trabajo y «entonces, el hombre libre cuesta poco más que el esclavo, mientras que es menos molesto y más productivo. Ser propietario de seres humanos deja de tener sentido debido a la gran multiplicación de esclavos, que se convierten en hombres libres...» ${ }^{3}$. Una población en crecimiento hace que la tierra se vuelva escasa. Las haciendas cultivadas por trabajadores libres o por arrendatarios sin ninguna obligación no económica pueden producir ahora rentas de la tierra que el Estado puede gravar para, por ejemplo, mantener un ejército.

La experiencia esclavista del sur de Estados Unidos se ajusta a la hipótesis «con demasiada simplicidad», pensó Domar, al igual que el comienzo de la servidumbre en Rusia y en Polonia-Lituania y el inicio de la servidumbre y su desaparición en el siglo XIII en Europa occidental. No obstante, Domar no puede explicar por qué no reapareció la servidumbre en Europa occidental tras la peste negra por un cambio a técnicas menos intensivas en trabajo (cría de ovejas), atribuyéndolo con renuencia a factores políticos exógenos. La disminución de la población pudo no ser uniforme entre las haciendas, afirmó Domar, haciendo que los terratenientes que habían perdido en términos relativos más siervos favorecieran la libertad de movimiento de los campesinos, mientras que los que habian perdido menos se opusieran. Desunidos, los terratenientes no pudieron ejercer presión sobre el gobierno para que hiciera lo que ellos querían, y dejaron abierta la puerta para que otros la ejercieran. Así, la presión existente detrás de la legislación en la Inglaterra de Ricardo II puede que no procediera de los terratenientes feudales, sino de los pequeños propietarios. En general, en una economía con trabajo escaso y tierra abundante de calidad uniforme, nunca existirán simultáneamente tierras libres, campesinos libres y terratenientes no trabajadores, aunque sí lo harán cualesquiera dos de ellos. La combinación que se encuentre dependerá del gobierno.

2. La economía colonial de Paraguay se caracterizó, en primer lugar, por la esclavitud de los indios americanos y, a partir de mediados de 1550 , por dos versiones de una forma de servidumbre, la «encomienda yanacona», que escondía, en realidad, la antigua esclavitud, y la «encomienda mitaria», más parecida a la servidumbre europea. Las encomiendas eran concesiones reales del trabajo de los indios a destacados españoles («encomenderos»), a quienes la Corona permitía recaudar en forma de trabajo los tributos que, de otro modo, los indios habrían tenido que pagar al rey ${ }^{4}$. A cambio de ello,

\footnotetext{
${ }^{3}$ Domar (1970), p. 23.

Pastore (1972), p. 12.
} 
los encomenderos tenían que proteger, evangelizar y aculturar a los indios a su cargo, prestar servicios militares para defender la colonia y pagar determinados impuestos al Tesoro Real ${ }^{5}$. Los indios sometidos a las encomiendas yanaconas vivían bajo la vigilancia estrecha de los encomenderos a quienes habían sido encomendados, y les servían continuamente. Los indios sometidos a la encomienda mitaria estaban confinados en pueblos y se turnaban para prestar servicios de trabajo, normalmente durante dos meses seguidos. Ambas formas de encomienda decayeron notoriamente hacia la década de 1630; sin embargo, las encomiendas en decadencia y los "pueblos de indios», en los que se hallaban los indios «mitayos», persistieron durante todo el período colonial. Junto a las haciendas en las que se utilizaba el trabajo en encomienda y los pueblos de indios apareció un pequeño campesinado mestizo, de habla guarani, que creció gradualmente en importancia, y cuyas granjas de tamaño familiar se extendieron de manera particularmente rápida en las últimas décadas del dominio colonial.

La esclavitud indígena apareció pronto en la colonización española de Paraguay. Las tribus de la zona situada al oeste del río Paraguay constituían una amenaza tanto para los españoles, que pretendian alcanzar Perú, como para las tribus de habla guaraní de la zona de Asunción. Se establecieron alianzas hispano-indias mutuamente beneficiosas $y$, en las expediciones conjuntas hacia el oeste, se hicieron numerosos prisioneros, que se dividían como esclavos entre los españoles y sus aliados indios. Estas alianzas se cimentaron según la costumbre indígena, es decir, mediante uniones maritales polígamas de españoles con mujeres indias, a quienes los españoles trataban como esclavas y con las que comerciaban abiertamente. Estos «matrimonios» dieron lugar a una población mestiza, sobre la que se hablará más adelante, y a vínculos de parentesco entre españoles, indios y mestizos. El parentesco había regulado la provisión de servicios de trabajo voluntarios y recíprocos entre las tribus indígenas y, temporalmente, satisfizo los mismos fines entre los españoles y los indios. Sin embargo, el «cuñadazgo» pronto se convirtió en un medio de exigir el trabajo indígena forzado. La esclavización abierta de los indios aliados siguió al descubrimiento de que no se podía llegar a Perú a través del Río de la Plata. Resignados a la idea de quedarse en Paraguay, los españoles atacaron los asentamientos indios en busca de esclavos. Estas «rancheadas» buscaban especialmente mujeres indias, debido a su habilidad como cultivadoras, y, formalmente, se extendieron hasta $1555^{\circ}$.

$\mathrm{La}$ esclavitud, las fugas y las enfermedades hicieron disminuir con rapidez la población indígena, lo que llevó, a su vez, a que la administración

\footnotetext{
S Saeger (1981), p. 65.

${ }^{6}$ Susnik (1965), vol. 1, y Saeger (1981), p. 63.
} 
colonial aboliera la esclavitud india y la sustituyera por las menos duras encomiendas. Los oficiales de la Corona consiguieron imponerlas finalmente en 1556, cuando el gobernador provincial distribuyó en encomiendas mitarias a 27.000 indios adultos y fuertes (equivalentes a una población de 100.000 personas) entre una parte de los españoles de Asunción. Los indios mitayos también estaban sometidos a la «congregación», una política que suponía el reasentamiento de los mitayos en «pueblos de indios» a los que los españoles tenían vedado el acceso ${ }^{7}$. La encomienda se produjo independientemente del reasentamiento, especialmente al principio. De hecho, los primeros pueblos de indios permanentes no se fundaron hasta la década de 1580 , un cuarto de siglo después de que se distribuyeran las primeras encomiendas mitarias ${ }^{8}$. Los indios «recalcitrantes» que se negaban a someterse a la encomienda podian ser obligados a hacerlo en «guerras justas», desencadenadas a tal fin, es decir, podían ser reducidos a esclavitud. Sometidos a la más estrecha vigilancia en los hogares, granjas y ranchos de los españoles, estos esclavos no podían, sin embargo, ser vendidos libremente por sus propietarios, sino que tenían que revertir primero a la Corona antes de volver a ser asignados a otro español, lo que es asimismo una característica de la encomienda mitaria. Se llegó a considerar que pertenecían a otra encomienda, la encomienda "yanacona», encubriendo y prolongando, así, la esclavitud en una forma restringida?.

El «nuevo» sistema no funcionó bien, por motivos que los contemporáneos atribuyeron al sistema de incentivos establecido en las encomiendas. Los encomenderos abusaron de sus privilegios y eludieron sus obligaciones contractuales. Por ejemplo, traspasaron los indios mitayos a las encomiendas yanaconas y se libraron de los servicios militares comprando cargos gubernamentales que eximían a su titular de su prestación ${ }^{10}$. Tres conjuntos sucesivos de ordenanzas reales observaron los abusos y legislaron en su contra, pero no hubo alivio para los indios guaranies hasta que los jesuitas comenzaron a fundar misiones al sudeste de Asunción en la década de $1610^{\prime \prime}$. Así, la población indígena continuó disminuyendo, y parece que, a comienzos del siglo xviI, se había reducido a una fracción de su tamaño original ${ }^{12}$. Entonces se hicieron intentos de extender la encomienda a los mestizos y de introducir esclavos africanos, pero, por lo general, no tuvieron éxito debido

Tobre la congregación, véase Burns (1972), p. 36.

8 Véase Durán Estrago (1987), pp. 93-164.

- Véase Zavala (1977).

${ }^{10}$ Saeger (1981), p. 74.

"Véanse Chaves (1969-1970), pp. 107-120, y Armani (1986).

12 Para una estimación de una cota inferior, véase López (1975), pp. 31-37, y para una cota superior, Garavaglia (1983), pp. 160-161. 
a las prohibiciones legales. Desde entonces, la encomienda de la mita —aunque aún valiosa - languideció ${ }^{13}$.

El resto del siglo xviI y los comienzos del siglo xviII estuvieron marcados por la contracción económica y la ausencia de inmigración. La diezmada población india había quedado «reducida» a los pueblos de indios ${ }^{14}$. En las tierras abandonadas que habían ocupado antaño, comenzaron a aparecer granjas familiares cuyos propietarios eran campesinos mestizos de habla guaraní, sobre todo después de que el comercio de productos agrícolas aumentara a finales del siglo xviII y principios del XIX ${ }^{15}$. La mayor producción de yerba mate en el Norte y de tabaco en el Este hizo crecer la demanda de tierra, al igual que la demanda derivada de hierba para el ganado, que se hizo particularmente importante tras la liberalización borbónica del comercio en la década de $1770^{16}$. Los precios de la tierra aumentaron, aparecieron rentas de la tierra y los mestizos invadieron las tierras de los pueblos de indios. Los salarios también crecieron, los campesinos sin tierra emigraron a las zonas con un crecimiento más rápido y se observó una inmigración relativamente grande ${ }^{17}$. La mayor demanda de tierra y de trabajo contribuyó a ampliar la frontera y aumentó la importancia relativa del estrato de pequeños propietarios campesinos. Además, las reformas borbónicas alentaron el desarrollo de empresas estatales, cuya demanda de trabajo indígena reactivó la política de la administración colonial del siglo xvir de no conceder nuevas encomiendas y de obligar a las vacantes a revertir a la Corona ${ }^{18}$. El sistema continuó funcionando en esta línea para ser abolido finalmente en 1812 , es decir, tras la independencia.

3. Las ofertas de factores se dieron en Paraguay en las proporciones de las hipótesis de Domar, es decir, había una pronunciada escasez de trabajo indígena en relación con la tierra ${ }^{19}$. Sin embargo, la esclavitud no fue resultado de la intervención de la administración colonial. Por el contrario, la Corona presionó para acabar con la esclavitud indígena e instituyó en su lugar las encomiendas, aboliendo legalmente la esclavitud indígena a mediados del siglo xvi (excepto en los casos de las guerras justas). Además, la esclavitud indígena apareció a pesar del hecho de que la demanda de trabajo

${ }^{13}$ Véanse Armani (1986), López (1975) y Velázquez (1972), respectivamente.

${ }^{14}$ Véase Velázquez (1982).

is Véase Garavaglia (1983), pp. 353-379, y (1987), pp. 193-260.

16 Véase Cooney $(1987 a)$ y (1987 b). Para el auge de finales del siglo xviII, véase Cooney (1977).

17 Véanse Ferrer de Arrellaga (1985) y Cooney (1982-1983), respectivamente.

18 Véase Cooney (1979) y (1980); para la reversión de la encomienda a la Corona, véase Saeger (1981), p. 77.

${ }^{19}$ Véase Service (1954), p. 14. 
esclavo procedía de las necesidades de producción de lo que era esencialmente una economía de subsistencia, no de exportación. Parece que, en Paraguay, la esclavitud indígena fue creada por terratenientes que utilizaron la coacción militar necesaria para su mantenimiento y reproducción a su propia costa, y a pesar de que no estaban produciendo una mercancía para su venta en el extranjero. La escasez de trabajo alentó también la introducción de las encomiendas, que requerían el tipo de intervención gubernamental directa inspirada por las consideraciones de Hacienda pública sugeridas por Domar. Por lo tanto, la afirmación de Domar de que la esclavitud requiere la intervención gubernamental no se ve corroborada, pero sí lo es la hipótesis relativa a la servidumbre. No obstante, Domar considera el comportamiento gubernamental como una variable política exógena y deja la explicación completa de su comportamiento a los expertos en ciencia política. Así, la hipótesis especifica de forma insuficiente el papel del gobierno.

La servidumbre o la esclavitud desaparecerán como resultado del crecimiento de la población, postuló Domar, aunque no sugirió qué fuerzas consistentes con la lógica de una economía esclavista o feudal originarían ese crecimiento. De hecho, la esclavitud indígena dio lugar a una disminución de la población, que no cesó cuando se instituyeron las encomiendas, y que, finalmente, llevó a la reducción de sus fuentes de abastecimiento y al consiguiente estancamiento. La hipótesis de Domar no prevé este efecto negativo sobre la población. Además, era de esperar que las encomiendas de Paraguay se extendieran en ese momento a la creciente población mestiza, al igual que Domar esperaba que, tras la peste negra, volviera la servidumbre a Europa. Sin embargo, aunque se hicieron algunos intentos en esta dirección, no se observó esta extensión. Por último, más que desaparecer porque el trabajo se volviera abundante y barato, la encomienda mitaria fue abolida en el contexto de una escasez general de trabajo y de un aumento de los salarios. Así, pues, la hipótesis de Domar parece ser inconsistente con la abolición de las encomiendas.

Que de la esclavitud y la servidumbre surgiera un campesinado libre plantea otro problema para la hipótesis de Domar, dado que éste sugiere que un campesinado libre precedió a la servidumbre o a la esclavitud. Además, la hipótesis postulaba que la esclavitud o la servidumbre desaparecerían debido a un aumento de la población que haría que el trabajo fuera abundante y la tierra escasa, y que a los terratenientes les mereciera la pena despedir a sus esclavos y contratar trabajadores libres. Suponiendo que la creciente población esclava llegara a ser libre, debido a su abundancia en relación con la tierra, sería de esperar que se transformara en una mano de obra libre y asalariada, no en el campesinado libre que floreció en Paraguay. Además, las especiales características étnicas mostradas por el cam- 
pesinado paraguayo exigen una explicación, que la hipótesis de Domar no puede dar, porque no se propuso para ese fin.

4. En general, unos derechos de propiedad privada bien definidos y ejercitados permitirán que las rentas procedentes de los recursos escasos sean acaparadas por sus propietarios, mientras que los recursos de propiedad común se explotarán en exceso y las rentas que, de otro modo, se hubieran derivado de ellos se disiparán, como en el caso clásico de las pesquerías ${ }^{20}$. Este análisis es aplicable a todos los recursos, incluido el trabajo. Dada una tierra abundante y uniformemente fértil y una competencia libre entre los terratenientes, surgirá un campesinado libre, siempre que los derechos de propiedad sobre todos los recursos - incluyendo el del propio trabajo- estén bien definidos y el gobierno los haga valer. Si esto es así, aunque el derecho a poseer tierras en propiedad privada esté restringido a un determinado sector de la población, no aparecerá la esclavitud o la servidumbre. Por otra parte, si el gobierno no consigue que se respeten los derechos de propiedad o los ejercita de forma diferenciada sobre el trabajo, es obvio que la esclavitud es un resultado posible. Los distintos resultados se deben claramente a diferentes definiciones y formas de hacer respetar los derechos de propiedad por parte del gobierno. Así, la intervención gubernamental parece ser tanto un requisito para la aparición de un campesinado libre, o de una clase de terratenientes y otra de trabajadores rurales asalariados, como lo es para la aparición de la servidumbre. Por el contrario, la intervención gubernamental no parece una condición necesaria para la esclavitud, que se puede imponer mediante la asociación de terratenientes privados. El caso en estudio sirve de ejemplo para esto. Los reyes españoles poseían la tierra y el trabajo debido a una bula papal, pero no quisieron o no pudieron ejercitar rígidamente sus derechos de propiedad. Por consiguiente, los españoles consideraron inicialmente a los indígenas como un recurso de propiedad común y explotaron su trabajo como hubieran hecho con cualquier otro recurso de esta naturaleza. De manera poco sorprendente, el resultado no fue un campesinado libre, sino la esclavitud y la despoblación indígena. De hecho, al no hacer valer sus derechos de propiedad sobre el trabajo indígena y dejar que los terratenientes esclavizaran a los indios, la Corona permitió que la tasa de rendimiento privada excediera la tasa de rendimiento social, aumentando, así, los incentivos para que los españoles colonizaran el Nuevo Mundo a costa de agotar el recurso del trabajo indígena. La analogía entre la pesca en el océano y la caza de esclavos se puede aplicar también de forma satisfactoria a la esclavitud de los indios americanos en Paraguay ${ }^{21}$.

20 Véase Gordon (1965).

"Véase Thomas y Bean (1974). 
Ocupémonos ahora de las encomiendas. La apropiación de los recursos de trabajo reales por parte de los esclavistas y la despoblación resultante hubieran agotado finalmente a la población indígena sujeta a tributos y disipado las rentas que procedían de ella. Para poner fin a este despilfarro de recursos, la Corona tuvo que excluir a los encomenderos, interviniendo y reafirmando sus derechos de propiedad sobre el escaso trabajo. Y lo hizo mediante la política de la congregación, que confinaba a los indios a pueblos y restringía el acceso de los españoles a esos pueblos. Sin embargo, para conseguir parte de las rentas del trabajo, la Corona tuvo, además, que vender o arrendar los derechos recuperados a agentes privados, o, alternativamente, utilizar los recursos de trabajo en empresas reales. Vender los derechos de propiedad reales habría dado lugar simplemente a la esclavitud indígena sin límites, que había sido abolida legalmente a mediados del siglo xvi. Por otra parte, arrendar los derechos por una serie de años no violaba las leyes existentes. El arriendo de los derechos durante un período de años dio origen a la encomienda yanacona, mientras que su arriendo por una parte del año durante un período de varios años dio lugar a la encomienda mitaria. Sin embargo, el arriendo creó incentivos para que los encomenderos depreciaran el recurso durante el período que duraba la concesión, e hizo necesario que la Corona concibiera algunas reglas sobre su uso y algunos medios para imponer dichas reglas. En otras palabras, las encomiendas mitarias crearon un problema de agencia.

Este análisis es consistente con el punto de vista de la obtención de rentas de los Estados mercantilistas, que afirma que dichos Estados consiguen ingresos proporcionando derechos de monopolio generadores de rentas a pre cios que reflejan la capacidad del monarca para la discriminación de precios. Los incentivos de la Corona para arrendar sus derechos sobre el trabajo indio a agentes privados fueron mayores cuanto más pobre y más cercana a la frontera estuviera la colonia, dado que la baja productividad laboral de la población indígena significaba que el rendimiento monetario de los tributos que pagaban en especie era probablemente más bajo que el coste de recaudarlos, sin contar los costes de defender la colonia. Por otra parte, cuando, a finales del siglo xvirI, los costes de defensa disminuyeron, la Corona promovió empresas estatales y los salarios se elevaron, los incentivos de la Corona para recuperar los recursos de trabajo que había arrendado aumentaron. Predeciblemente, la administración colonial escogió recuperar los derechos reales sobre el trabajo y utilizar el trabajo indio en las empresas estatales.

Se puede concluir, por tanto, que las encomiendas pretendieron regular la esclavitud que había surgido del libre juego de los objetivos de la maximización privada en el contexto de unos derechos de propiedad que no estaban bien definidos ni ejercitados. Las encomiendas trataron de preservar las exis- 
tencias reales de trabajadores indios y de aumentar la participación de la Corona en el excedente sobre la subsistencia que los usuarios privados del trabajo indígena extraían, es decir, de cambiar la distribución de la renta que resultaba de las disposiciones institucionales propias de la esclavitud. Esto exigía nuevas disposiciones institucionales, que se establecieron mediante una transacción mutuamente beneficiosa entre el gobierno de la Corona y los terratenientes. La Corona transfirió temporalmente sus derechos sobre el trabajo de los indios a los encomenderos, que, a cambio de ello, pagaban algunos impuestos y asumían la responsabilidad de prestar servicios sociales y de defensa. Los encomenderos aceptaron el cambio porque tenían una ventaja comparativa en relación con la Corona para obtener trabajo de sus encomendados y para consumir lo que producían. Además, habían adquirido una experiencia militar considerable durante la conquista y se podían organizar en una milicia eficaz para defender la colonia.

Las encomiendas se deben contemplar como una forma poco común de cesión por parte del gobierno a un particular de la recaudación tributaria que hacía que las dos partes compartieran las rentas derivadas de los escasos recursos de trabajo pertenecientes a la Corona. También eran un sistema discriminatorio de asignación de trabajo, que sus beneficiarios querían conservar y los perjudicados deseaban reformar. Dadas las necesidades de defensa del siglo Xvir, y la posterior demanda de trabajo indígena por parte de las empresas estatales, no hay que sorprenderse de que las encomiendas persistieran mientras duró el dominio colonial. Por otro lado, dado que a comienzos del siglo XIX la gran mayoría de los paraguayos eran campesinos sin encomiendas, era de esperar que las encomiendas se abolieran tras la independencia, como, de hecho, se hizo. Así, pues, las condiciones que llevaron a la abolición de la encomienda en Paraguay parecen haber surgido de la lógica interna de las condiciones económicas existentes, y recuerdan a aquéllas a las que Domar atribuyó la no reaparición de la servidumbre en Inglaterra.

Consideremos ahora al campesinado mestizo libre. Debido a la ausencia de inmigración, los mestizos ocuparon la posición de «criollos», hijos de españoles nacidos en las Indias, aunque los cargos públicos y las encomiendas se asignaban preferentemente a los españoles de la península. Así, después de que se distribuyeran las primeras encomiendas, los mestizos dejaron Asunción para dirigirse a las zonas del Norte y del Este, donde había concentraciones relativamente grandes de indios aún sin encomendar, que se podían someter a la encomienda mitaria o convertir en esclavos. Sin embargo, una vez que desapareció esta población, los mestizos tuvieron que depender de su propio trabajo y de la tierra, aún abundante, para su sustento, es decir, se convirtieron en campesinos. Cuando la escasez de trabajo se hizo más pro- 
nunciada y las encomiendas entraron en decadencia, los mestizos no se vieron sujetos a la encomienda, al no ser esto legalmente posible. Así, pues, fue la intervención del gobierno para hacer valer los derechos de propiedad la que permitió que el campesinado libre continuara siéndolo, cuando las fuerzas económicas lo hubieran llevado a su esclavitud. De este modo, debido a que el gobierno encomendó el trabajo indígena a las reservas y permitió que los españoles y los mestizos poseyeran tierras, aparecieron simultáneamente siervos indígenas, terratenientes que no trabajaban sus tierras y campesinos mestizos libres. Así, surgió de hecho un modelo cuya aparición Domar consideró imposible: la asignación discriminatoria y la imposición por parte del gobierno de derechos de propiedad privada sobre el trabajo y la tierra, con el fin de posibilitar que el Estado y los particulares compartieran las rentas de los escasos recursos de trabajo, resultaron en una estructura de clases y en un sistema de tenencia de tierras de características étnicas especiales.

Basándonos en esta discusión, el enunciado provisional de la hipótesis reformulada sería el siguiente: suponiendo la existencia de tierras homogéneas, abundantes y uniformemente fértiles, aparecerá un campesinado libre siempre que los derechos de propiedad privada sobre todos los recursos estén claramente definidos y ejercitados por un gobierno financiado con los tributos directos e indirectos recaudados a los propios campesinos. Siempre que la tierra sea abundante y uniformemente fértil, la introducción de un tercer factor, el capital, no alterará significativamente los resultados. La restricción gubernamental del derecho de poseer tierra a una sección de la población dará lugar a una clase de trabajadores rurales asalariados, y la estructura de la Hacienda pública se modificará, consecuentemente. Si el trabajo es escaso, pero la tierra es abundante y uniformemente fértil, y los derechos de propiedad sobre todos los recursos se asignan al gobierno, pero no están bien definidos o ejercitados, el comportamiento maximizador llevará a los agentes privados con mayor capacidad de coacción a hacer esclava a una población militarmente inferior y a extraer los excedentes sobre la subsistencia que pueda producir. El intento de esclavizar a los trabajadores dará lugar a una disminuición de la población de la que proceden los esclavos, de una manera parecida a la predicha por la teoría de los recursos de propiedad común. El agotamiento de este recurso y la disipación de las rentas puede obligar al gobierno a intervenir para preservarlo y extraer las rentas derivadas de él, siempre que se considere que las ganancias de hacerlo superen a los costes. Conservar este recurso implica proteger a los trabajadores, lo que exigirá que el gobierno separe a los usurpadores de los trabajadores. Extraer las rentas del trabajo requerirá que el gobierno ponga en práctica un plan de reparto de dichas rentas, es decir, que ceda su recaudación a cambio de la provisión de ciertos bienes públicos. Para ello, el gobierno vinculará los tra- 
bajadores a los recaudadores de tributos y los confinará a sus asentamientos, es decir, restringirá la competencia por trabajadores y la movilidad laboral. Alternativamente, el gobierno puede utilizar los recursos de trabajo en sus propias empresas. La opción que se elija dependerá de las alternativas que tenga el gobierno en cuanto a la Hacienda pública, del coste de proporcionar la defensa, del precio del trabajo y de su capacidad de dirigir empresas comerciales. En cualquier caso, serán necesarias las restricciones gubernamentales sobre el derecho de poseer tierra propia y trabajo. En caso de que las restricciones se establezcan según las etnias, las diferencias de clases resultantes y el sistema de tenencia de tierras mostrará también unas características étnicas similares.

Es probable que la población esclava, debido a que se le priva de una parte mayor o menor del excedente sobre la subsistencia que produce, crezca a un ritmo menor que el campesinado mestizo. A medida que el trabajo esclavo se hace relativamente más escaso, los terratenientes con concesiones de trabajo disminuirán como proporción de la población, al igual que la presión que pueden ejercer sobre el gobierno para mantener un sistema discriminatorio de asignación del trabajo. Por el contrario, a medida que el campesinado libre alcance una mayor proporción del total de la población, aumentarán los incentivos para que apoye la abolición del sistema de encomiendas, y la creciente influencia campesina sobre el gobierno puede llevar a la abolición de la servidumbre. Sin embargo, en caso de que el gobierno haya recuperado las concesiones de trabajo que hizo originalmente, resistirá a las presiones campesinas en favor de la abolición. En este caso, si el propio campesinado no puede persuadir al gobierno, el aumento de la población puede hacer que el gobierno considere las crecientes rentas de la tierra como un sustituto no rentable de los ingresos tributarios basados en las cada vez menores rentas del trabajo, aboliéndose, así, la servidumbre.

5. Para contrastar la hipótesis reformulada debemos establecer su capacidad de explicar otras características de la economía colonial de Paraguay distintas a las que sugirieron la reformulación. Se pueden mencionar, al menos, tres ejemplos. En primer lugar, el hecho de que a medida que las encomiendas entraron en decadencia a comienzos del siglo xvir, la Corona declaró exentos a los indios de las misiones jesuitas de las encomiendas y denegó varias peticiones de los encomenderos para cancelar dicha exención; en segundo lugar, que la Corona también prohibió la importación de esclavos africanos para reponer la menguante oferta de trabajo indio; $y$, en tercer lugar, que en el siglo xviri, como la Corona no concedió nuevas encomiendas y retomó la posesión de aquéllas cuyo plazo había acabado, su participación en los deberes de defensa aumentó. 
La población indígena de las misiones jesuitas creció con rapidez desde sus comienzos. Por el contrario, la de las misiones franciscanas no empezó a crecer hasta el siglo xviII y, entonces, sólo muy lentamente. Además, bajo la dirección de sus mentores jesuitas, los indios de estas misiones contribuyeron eficazmente a la defensa $y$, por añadidura, pagaron puntualmente sus tributos en efectivo. Cuando se congregó a los indios en misiones bajo vigilancia jesuita, se les separó de los españoles y se les eximió de las encomiendas, los trabajadores indígenas produjeron unos rendimientos mucho más elevados que cuando se hallaban confinados en pueblos bajo vigilancia franciscana, menos aislados de los españoles y sujetos a la encomienda. La Corona no tenía motivos para ceder ante los encomenderos y reimponer la encomienda sobre los indios de las misiones jesuitas $\mathrm{y}$, de hecho, no lo hizo. Que, a medida que las encomiendas entraron en decadencia, la Corona hubiera prohibido a los encomenderos importar esclavos africanos es, también. consistente con la hipótesis. Si se hubiera permitido a los encomenderos importar esclavos africanos, habrían pasado del trabajo en encomienda al trabajo esclavo africano; los compromisos de defensa que habían adquirido con sus encomiendas también habrían disminuido consecuentemente. Al prohibir la importación de esclavos africanos, la Corona redujo la capacidad de los encomenderos de sustituir el trabajo indio por el trabajo africano y les obligó a continuar con sus compromisos de defensa originales. Por último, la contribución de los encomenderos a la defensa disminuyó en el siglo xvirI, conforme la Corona dejó de conceder nuevas encomiendas y volvió a tomar posesión de aquellas cuyo plazo había acabado. Como era de esperar, la participación de la Corona en los deberes de defensa aumentó, en consecuencia. El viejo sistema por el que la administración colonial obtenía de los particulares una contribución a la defensa a cambio de concesiones de trabajo fue desmantelado. En su lugar, una reforma militar instaló a un ejército semiprofesional remunerado por la Corona en efectivo, no en trabajo o en tierra o en ambos.

En conclusión, el énfasis de Domar en la escasez relativa de trabajo en relación con la tierra como una de las causas de la esclavitud o la servidumbre agrícola está plenamente justificado. Sin embargo, su identificación de la esclavitud con la servidumbre no lo está. A pesar de las semejanzas entre estas dos formas de trabajo forzado, existen las suficientes diferencias entre ellas como para justificar su tratamiento por separado. El caso estudiado aquí sugiere que el hecho de que la escasez relativa de trabajo en relación con la tierra dé lugar a la esclavitud o a la servidumbre depende de la medida en que el Estado haga valer los derechos de propiedad, que, a su vez, dependerán de la tasa de rendimiento de la inversión en esa actividad de los escasos recursos del Estado en comparación con otras. En Paraguay, 
la esclavitud indígena apareció cuando el Estado dejó de hacer valer sus derechos de propiedad privada sobre el trabajo indígena y permitió que sus súbditos peninsulares consideraran a los indígenas un recurso de propiedad común. La explotación del trabajo indígena, propiedad de la Corona, por parte de terratenientes privados, como un recurso de propiedad común, llevó al agotamiento de este recurso y a la disipación de las rentas que hubieran correspondido a la Corona. A medida que este recurso se hizo más escaso y, por lo tanto, más valioso, y para evitar que se completase su agotamiento y la disipación de las rentas por él generadas, la Corona trató de regular la explotación del trabajo indio mediante la encomienda y la congregación. Estas instituciones reguladoras tenían características muy semejantes a los planes para gestionar los recursos de acceso abierto como las pesquerías. Pretendían obstaculizar el acceso a este recurso y la disipación de las rentas que podían rendir para la Corona. Sin embargo, el sistema no funcionó bien hasta que los indios se congregaron en las misiones jesuitas, se separaron de los españoles y, además, se les eximió de las encomiendas. El crecimiento de la población mestiza, eximida legalmente de las encomiendas, hizo que, con el tiempo, el trabajo fuera relativamente más abundante y la tierra comparativamente más escasa, una tendencia que se vio exacerbada cuando las reformas borbónicas incrementaron el comercio exterior y la inmigración. A medida que la tierra y el comercio exterior sustituyeron al trabajo como la fuente principal de recaudación tributaria, se abandonaron las encomiendas en favor de otras medidas institucionales con las que el Estado trató de obtener ingresos y proporcionar defensa.

(Traducción: Angeles Conde.)

\section{BIBLIOGRAFIA}

Armani, Alberto (1986): Ciudad de Dios y Ciudad del Sol. El «estado» jesuita de los guaranies (1609-1769), México, Fondo de Cultura Económica.

Burns, E. Bradford (1972): Latin Amertca, a concise interpretive bistory, Englewood Cliffs (Nueva Jersey), Prentice Hall.

Chaves, Julio César (1969-1970): «Las ordenanzas de Ramírez de Velasco, Hernandarias y Alfarom, Historia Paraguaya, vol. 13, pp. 107-120.

Cooney, Jerry W. (1977): «An Ignored Aspect of the Viceroyalty of the Rio de la Plata», Intercambio Internacional, vol. 2, núm. 1 (enero), pp. 10-13.

- (1979): «A Colonial Naval Industry: The Fábrica de Cables of Paraguay», Revista de Historia de América, vol. 87 (enero-junio).

- (1980): «Paraguayan Astilleros and the Platine Merchant Marine, 1796-1806», The Historian, vol. 43, núm. 1 (noviembre), pp. 55-74. 
Cooney, Jerry W". (1982-9183): "Foreigners in the Intendencia of Paraguay", The Americas, vol. XXXIX, pp. 333-358.

- (1987 a): «The Yerba Mate and Cattle Frontier of Paraguay, 1776-1811: Social, Economic, and Political Impact» (manuscrito).

- (1987 b): «Bureaucrats, Growers and Defense: The Royal Tobacco Monopoly of Paraguay» (manuscrito)

Domar, Evsey (1970): "The Causes of Slavery and Serfdom: A Hypothesis», Journal of Economic History, vol. 30 (marzo), pp. 18-32.

Durán Estrago, Margarita (1987): Presencia franciscana en el Paraguay: 1553-1824, Asunción, Universidad Católica.

Ferrer de ArRellaga, René (1985): Un siglo de expansión colonizadora: los orígenes d' Concepción, Asunción, Editorial Historia.

Garavagila, Juan Carlos (1983): Mercado interno y economía colonial, México, D. F.. Editorial Grijalbo.

- (1987): Economía, sociedad y regiones, Buenos Aires, Ediciones de la Flor.

Gordon, H. Scott (1965): «Economic Theory of Common Property Resources», Journal of Political Economy, vol. 62.

Lockhart, James, y Schwartz, Stuart (1983): Early Latin America, Cambridge, Cambridge University Press.

LóPEZ, Adalberto (1975): «Shipbuilding in Sixteenth Century Asunción del Paraguay», Mariner's Mirror, vol. 61, núm. 1 (febrero), pp. 31-37.

Pastore, Carlos (1972): La lucha por la tierra en el Paraguay, Asunción, Editorial Antequera.

SAEGER, James Schofield (1981): «Survival and Abolition: The Eighteenth Century Paraguayan Encomienda», The Americas, vol. 28 (julio), pp. 59-85.

Service, Elman R. (1954): Spanisb Guarani Relations in Early Colonial Paraguay, Westport, CT.

SusNik, Branislava (1965): El indio colonial del Paraguay, vol. 1: El guarani colonial, Asunción, Museo Etnográfico Andrés Barbero.

Thomas, Robert P., y Bean, Richard (1974): «The Fishers of Men: The Profit of the Slave Trade», Journal of Economic History, vol. 34, pp. 885-914.

Velázquez, Rafael Eladio (1972): «La población del Paraguay en 1682», Revista Paragua. ya de Sociología, vol. 9, núm. 24 (mayo-agosto), pp. 128-148.

- (1982): «Caracteres de la encomienda paraguaya en los siglos xviı y xvin», Historia Paraguaya, vol. XIX, pp. 115-163.

Zavala, Silvio (1977): Origenes de la colonización en el Río de la Plata, México, El Co. legio Nacional. 